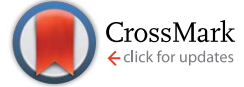

Cite this: RSC Adv., 2017, 7, 11537

\title{
Ultra-high aspect ratio functional nanoporous silicon via nucleated catalysts $\uparrow$
}

\begin{abstract}
Jatin J. Patil, ${ }^{a}$ Brendan D. Smith ${ }^{b}$ and Jeffrey C. Grossman ${ }^{\star b}$
Nanoporous silicon (NPSi) has drawn recent interest because of its potential in a range of applications such as battery anodes, photocatalysis, thermoelectrics, and filtration membranes. However, the inexpensive and scalable manufacturing of high aspect ratio porous structures on the nanometer scale has been difficult due to the reliance of current methods on complex and expensive equipment used for techniques such as anodization or photolithography. Here, we report a method of producing NPSi with sub-10 nm pore sizes and aspect ratios as high as $400: 1$ by leveraging the nucleation of sputtered noble metals on the Si surface, followed by metal-assisted chemical etching (MACE). The technique is capable of producing NPSi in an intrinsically scalable manner. Samples are characterized with SEM and TEM, along with vertical and horizontal FIB cross-sectional milling to elucidate the porous structure at several $\mu \mathrm{m}$ of depth within the substrate. Following preparation of the NPSi, it is functionalized with $\mathrm{Al}_{2} \mathrm{O}_{3}$ and $\mathrm{TiO}_{2}$ via atomic layer deposition (ALD). $\mathrm{TiO}_{2}$-functionalized NPSi exhibits reflectivity of $6-8 \%$ for visible wavelengths, and 2$3 \%$ in the infrared - showing its promise as a robust and functional porous substrate. The developed approach of employing MACE with sputtered nucleated catalysts facilitates the scalable fabrication of functional ultra-high aspect-ratio nanopores in silicon.
\end{abstract}

Received 13th January 2017
Accepted 9th February 2017

DOI: $10.1039 / \mathrm{c} 7 \mathrm{ra00562h}$

rsc.li/rsc-advances

especially for larger scale applications such as catalysis or filtration, a simple and scalable strategy is needed.

Metal-assisted chemical etching (MACE) has been widely explored as a method to efficiently etch silicon to produce complex extruded 3D structures such as X-ray diffraction grating $\mathrm{s}^{22}$ with high precision on the sub-micron scale. The technique was utilized by Chang et al. in combination with blockcopolymer lithography to form regular arrays of nanowires with aspect ratios of up to $220: 1,{ }^{23}$ as well as extensively in other work to show controllable extrusion of nanowires and nanostructures in silicon. ${ }^{24-27}$

The MACE process begins with deposition of noble-metal catalysts $^{28}$ on the silicon surface, followed by introduction to an acidic oxidizing solution of hydrofluoric acid (HF) and hydrogen peroxide $\left(\mathrm{H}_{2} \mathrm{O}_{2}\right)$. The reduction of $\mathrm{H}_{2} \mathrm{O}_{2}$ is catalyzed by the noble metal, which in turn locally injects holes $\left(\mathrm{h}^{+}\right)$into the silicon. ${ }^{29-32}$ This oxidizes the silicon, locally producing $\mathrm{SiO}_{2}$, which is subsequently dissolved by the HF present in the solution. The reaction scheme results in the continuous etching of the noble metal along preferred crystalline orientations, creating positive features that very closely match the shape of the patterned catalyst. ${ }^{33}$

NPSi can be generated via MACE by depositing noble metal nanoparticles on silicon to act as catalysts, ${ }^{34}$ where the etching rate is primarily limited by the diffusion of reactants and products to and from the noble metal at the pore bottom. ${ }^{35}$ However, using nanoparticles for etching has its own drawbacks - particle faceting results in different surface areas, where

${ }^{a}$ Department of Chemical Engineering, University of Waterloo, ON, Canada N2L 3G1 ${ }^{b}$ Department of Materials Science and Engineering, Massachusetts Institute of Technology, Cambridge, Massachusetts, USA 02139.E-mail: jcg@mit.edu

$\dagger$ Electronic supplementary information (ESI) available. See DOI: 10.1039/c7ra00562h 
surface area is proportional to etch rate and direction. ${ }^{36}$ The etching directionality of MACE is dependent on $\mathrm{h}^{+}$injection at the catalyst-silicon interface. ${ }^{37}$ Therefore, particles are prone to etch in unwanted directions if their largest facet is not perpendicular to the desired etch direction. Our recent work has demonstrated pore aspect ratios of over 100:1 using MACE with silica-coated gold nanoparticles, achieving sub-10 nm pore sizes with consistent, directional etching and a narrow size distribution over many square micrometers of substrate. ${ }^{38}$ However, this requires a relatively complex synthesis procedure, and would require uniform particles along with a sensitive monolayer deposition technique.

We demonstrate here a scalable method for the deposition of sub-5 nm noble metal nanoislands on the surface of Si, which subsequently yield ultra-high aspect ratio nanopores via the MACE process. The technique employs the DC magnetron sputtering of nominal gold and silver thin films (sub-1 nm thickness) under standard deposition conditions, which nucleate as Volmer-Weber island structures due to their low surface energies. These island structures have been studied extensively to elucidate film formation mechanics in magnetron sputtering. ${ }^{39,40}$ The method has been previously employed by Chung et al., where the film formation process is halted prior to full film coverage to investigate the plasmonic absorbance of $\mathrm{Ag}$ nanoislands pre- and post-annealing. ${ }^{41}$ In this work, we utilize a similar approach for the scalable deposition of sub-5 nm islands with 5-15 $\mathrm{nm}$ inter-particle spacing (refer to ESI $\dagger$ for nano-island spacing histograms). The use of magnetron sputtering also facilitates the deposition of island structures with planar catalyst-Si interfaces, which allows for more directional hole injection and subsequently a highly anisotropic etch. The approach developed here results in a fast, scalable method of producing nanoporous silicon with sub-10 $\mathrm{nm}$ pore size, extremely directional etching and aspect ratios as high as $400: 1$.

In addition to the capability of fabricating sub-10 nm ultrahigh aspect ratio pores in $\mathrm{Si}$, the possibility of creating functional porous substrates via the conformal deposition of catalytic materials is explored here through the atomic layer deposition (ALD) of titanium dioxide $\left(\mathrm{TiO}_{2}\right)$ - a popular photocatalyst that has been investigated extensively as a substrate for self-cleaning surfaces, water treatment, and hydrogen production. ${ }^{\mathbf{4 2 - 4 4}}$ The ability of ALD to deposit conformal layers with sub-nanometer resolution ${ }^{45}$ can be further leveraged for the fabrication of a wide array of functional devices. ${ }^{44,46,47}$

\section{Experimental}

(100) silicon wafers (B-doped, thickness: $275 \pm 25 \mu \mathrm{m}$, resistivity: $0.001-0.01 \Omega \mathrm{cm}$ ) were solvent cleaned using a standard acetone-IPA-DI water rinse. Dried wafers were sputtered with AJA ATC 2200 UHV Sputter Coater under pre-deposition pressure of $5-10 \times 10^{-8} \mathrm{~Pa}$, Ar flow of $40 \mathrm{sccm}$, and deposition pressure of 4 mTorr. Targets were DC magnetron sputtered at $125 \mathrm{~W}$. Deposition rates were $3.2 \AA^{-1} \mathrm{~s}^{-1}$ for Au and $4.0 \AA^{-1}$ for Ag. Following deposition, substrates were placed into the MACE solution (5.33 M HF, $0.12 \mathrm{M} \mathrm{H}_{2} \mathrm{O}_{2}$ ). Reaction was terminated by washing with water and removal of substrates, followed by drying with a $\mathrm{N}_{2}$ gun.

\section{Atomic layer deposition on porous samples}

NPSi samples are coated using the Harvard CNS Benchtop ALD system. $\mathrm{Al}_{2} \mathrm{O}_{3}$ is coated via a static-flow process at $200{ }^{\circ} \mathrm{C}$. Precursors are trimethylaluminum and $\mathrm{H}_{2} \mathrm{O}$, with calculated growth rate of $1.14 \AA$ per cycle. $\mathrm{TiO}_{2}$ is coated via static process at $190{ }^{\circ} \mathrm{C}$. Precursors are tetrakis(dimethylamido)titanium and $\mathrm{H}_{2} \mathrm{O}$ with calculated growth rate of $0.45 \AA$ A per cycle.

\section{TEM cross section sample preparation}

Planar view lamellae were prepared at a depth of $4 \mu \mathrm{m}$ below the surface, extracted, and mounted to standard copper TEM grids using a FEI Helios 660 Focused Ion Beam instrument equipped with an Omniprobe.

\section{Characterization}

Zeiss Ultra Plus Field Emission SEM, FEI Helios 660 Focused Ion Beam (FIB) with SEM (and attached EDAX Energy Dispersive X-ray Spectroscopy [EDS] Detector), JEOL 2100 Transmission Electron Microscope, and Thermo Scientific K-Alpha+ XPS are used. Image statistics are analyzed using ImageJ and MATLAB.

\section{Results and discussion}

Deposition of nucleated noble metal islands for MACE is demonstrated here to be a promising strategy to produce porous silicon with sub-10 $\mathrm{nm}$ pore sizes. This method is both high-throughput and scalable, and demonstrates the versatility of the MACE technique to catalyze pore formation in a novel size-regime. While nanoparticles have previously been proposed as a solution to obtaining monodisperse pore size and spacing, they can exhibit inconsistency in their deposition and etching directionality. ${ }^{48}$ In addition, achieving highly ordered arrays of homogeneously spaced catalysts over large areas necessitates the use of ligands and very monodisperse particles, and requires precise control over chemistry and monolayer formation. ${ }^{49}$ The developed method of sputtering MACE catalysts removes this dependency on parameter-sensitive wet chemical processes and brings a simplified and established method of metal deposition, resulting in a simple two-step MACE synthesis process. The established approach is demonstrated in this work to be effective for the production of NPSi exhibiting morphological nanoscale homogeneity over many square centimeters, with no intrinsic limitations on the further scaling of the technique.

The process of sputtering nominally thin-films of metal causes the nucleation of homogeneously spaced and sized islands. ${ }^{50}$ The size and morphology of islands is influenced by surface defects on the substrate ${ }^{51}$ and the interfacial energies of the metals with $\mathrm{Si}^{52}$ where the metal surface energies $(\gamma)$ are $\gamma_{\mathrm{Ag}}$ $=1.246-1.250 \mathrm{~J} \mathrm{~m}^{-2}$, and $\gamma_{\mathrm{Au}}=1.500-1.506 \mathrm{~J} \mathrm{~m}^{-2} .{ }^{53}$ Due to their wetting behavior on the native oxide surface, Au and Ag films nucleate as isolated islands instead of a continuous film. SEM and TEM images of nucleated islands resulting from 
sputtering $3 \AA$ of $\mathrm{Au}$ and $\mathrm{Ag}$ are shown in Fig. 1, along with corresponding histograms of island size. Observed diameters of nucleated islands are $4.4 \pm 0.9 \mathrm{~nm}$ for Ag (images in Fig. 1a-c) and $2.0 \pm 0.9 \mathrm{~nm}$ for Au (Fig. 1d-f). The SEM images demonstrate the large-area coverage of the $\mathrm{Au}$ and $\mathrm{Ag}$ islands over the silicon substrate. This island formation is homogeneous over the entire sputtered and etched region of the silicon wafer. TEM images show the Volmer-Weber film nuclei. The advantages to this method over using conventional nanoparticle deposition or in situ nanoparticle growth are superior substrate-metal interface contact area, smaller particle size, narrower particle size distribution, and uniform catalyst spacing over large areas.

Following sputter deposition, the wafer is placed in the MACE etchant solution. Etching of silicon is enabled by localized silicon oxidation, facilitated via catalytic reduction of $\mathrm{H}_{2} \mathrm{O}_{2}$ on noble metal nanoparticles. This is followed by etching of $\mathrm{SiO}_{2}$ by $\mathrm{HF}$, allowing the metal nanoislands to continue etching normal to the Si surface. After etching, the nanopores of the NPSi are filled with $\mathrm{Al}_{2} \mathrm{O}_{3}$ via $\mathrm{ALD}$ to enhance imaging contrast and to preserve the porous morphology prior to characterization.

Characterization of pore sizes via image analysis, especially after Au-catalyzed MACE, is difficult due to the texturing of the Si surface during etching, a phenomenon possibly initiated by the formation and etching of Au-silicides in near proximity to the substrate surface. Diffusion of Au into Si has been noted at room temperature for $\mathrm{Si}$ treated with $\mathrm{HF}^{54}$ This has the potential to cause Au-silicide formation and further unwanted etching of the surface. Similar effects have been reported with $\mathrm{Ag}$ catalysts, with particular reference to the formation of a mesoporous Si layer around etching sites. ${ }^{55}$ Though the aforementioned surface degradation makes direct pore size measurement difficult, the size of the metal catalysts fabricated for MACE should closely match the etched feature sizes, as shown in previous work evaluating the quality and precision of MACE. ${ }^{56}$

A further degree of control over nanoisland size could be employed via silicon surface treatment prior to catalyst nucleation. Removal of native oxide with HF prior to noble metal deposition increases wettability of the films. This in turn is expected to cause a lower metal island contact angle, but also higher likelihood of silicide formation.

The effect of contact angle on etching characteristics can be elucidated by comparing the etching behavior of $\mathrm{Au}$ and $\mathrm{Ag}$ metal islands, which exhibit different wetting behavior. With its lower surface energy, $\mathrm{Ag}$ has a higher contact angle with Si than does $\mathrm{Au}$, thus forming more pronounced nanoislands, as seen in SEM (Fig. 1a and d). This, in turn, leads to more lateral etching on the surface prior to etching in the $\langle 100\rangle$ direction which is observed as linear tracks surrounding pores in $\mathrm{Ag}$ (Fig. 2c) when compared to Au, which has a lower contact angle (Fig. 2b).

To verify the presence of nanopores and examine the morphology within the bulk of the sample following etching, TEM images of horizontal cross-sections of NPSi and a control Si sample prepared via FIB at a depth of $4 \mu \mathrm{m}$ are compared. The resulting images demonstrate the presence of pores at depths beyond $4 \mu \mathrm{m}$ into the substrate for the sample etched with sputtered Au, as visible in Fig. 3b. The ability to extract a $100 \mathrm{~nm}$ lamella at a $4 \mu \mathrm{m}$ depth while maintaining the porous morphology also demonstrates the structural stability of the porous structure. In addition to the deposition of $\mathrm{Al}_{2} \mathrm{O}_{3}, \mathrm{ALD}$ is utilized here for the conformal coating of the NPSi pore walls a

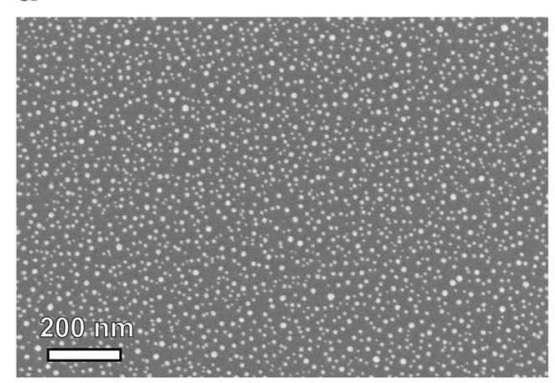

d

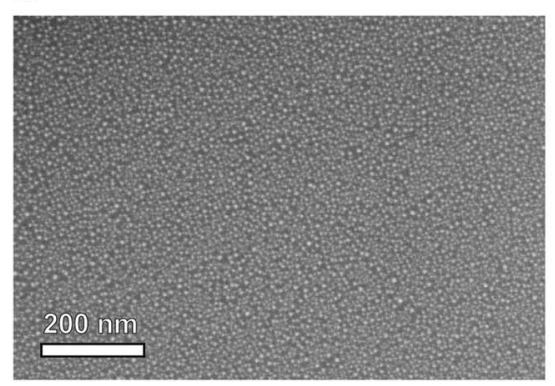

b

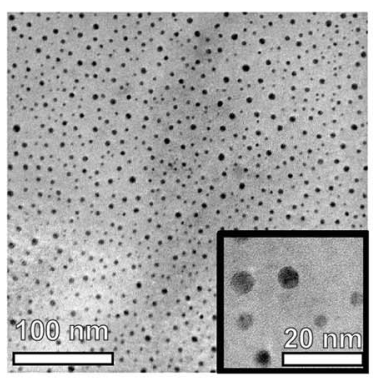

e

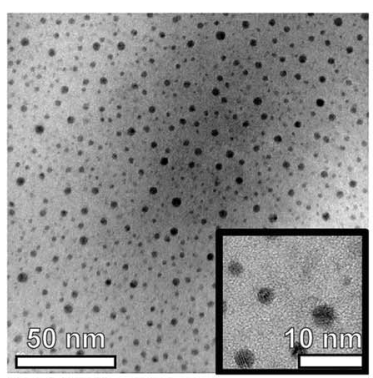

C

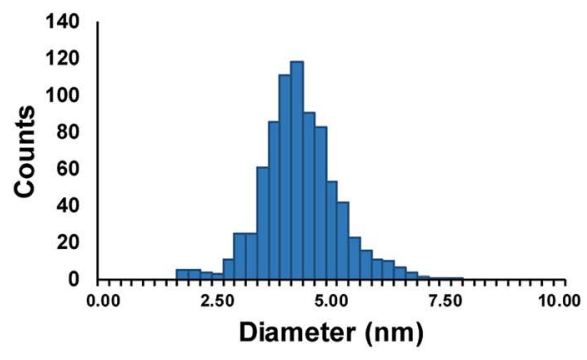

f

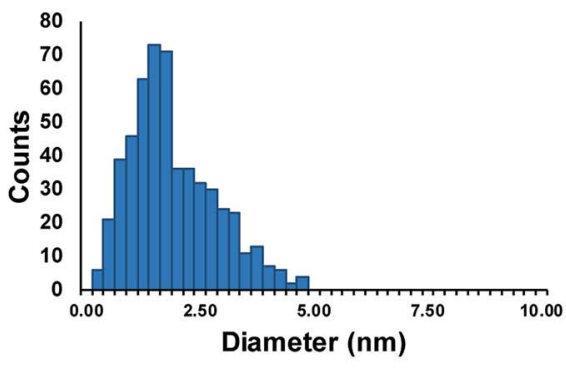

Fig. 1 Images of sputtered nucleated Ag taken with (a) SEM, (b) TEM. (c) Particle size histogram for Ag catalysts generated from the TEM image. Images of sputtered nucleated Au taken with (d) SEM, (e) TEM. (f) Particle size histogram for Ag catalysts generated from the TEM image. Target film thickness is $3 \AA$ for both metals. 
a
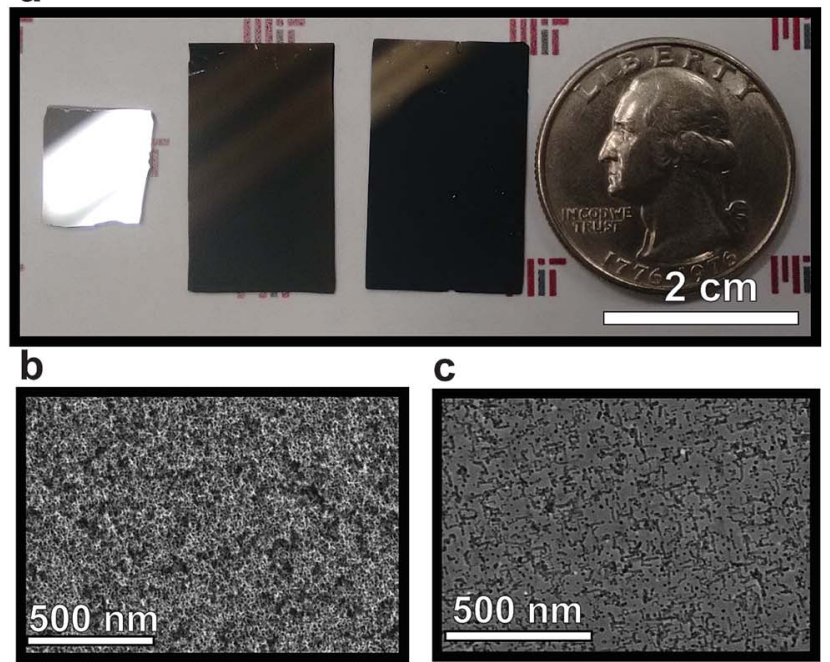

d

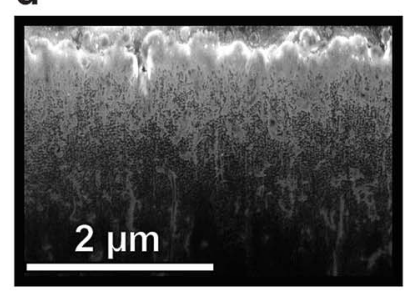

e
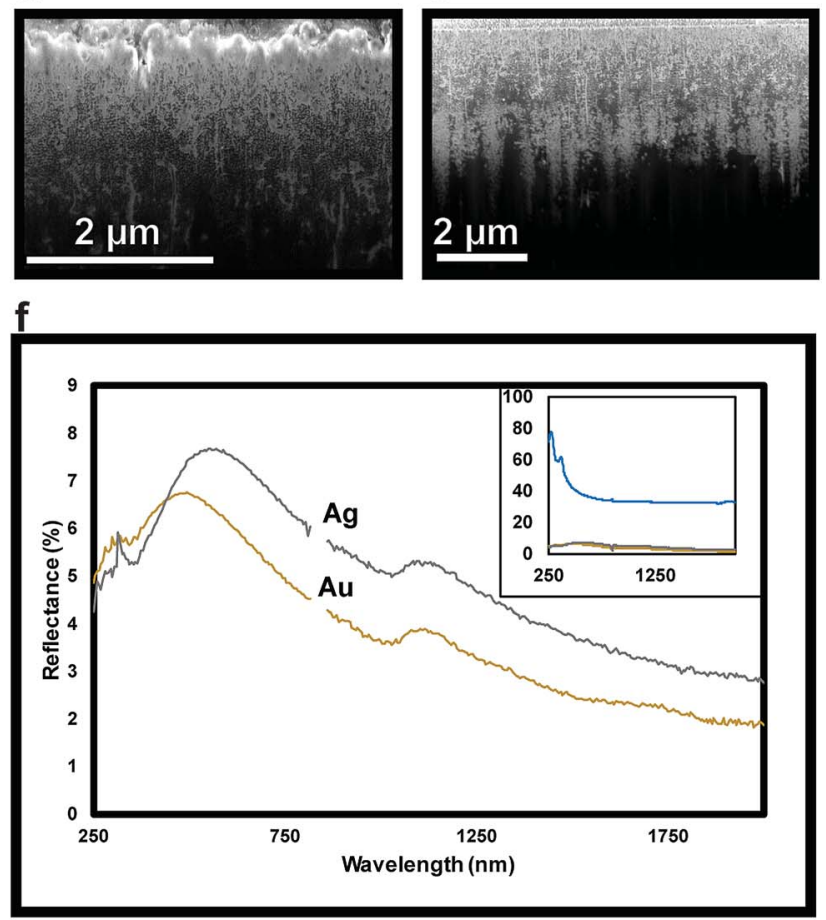

Fig. 2 (a) Macroscopic view of (left to right) bare Si, Si etched with Au, $\mathrm{Si}$ etched with Ag, and a 25-cent coin for scale. SEM images of porous Si surfaces etched with (b) Au and (c) Ag SEM images of focused ion beam (FIB) milled cross-sections of (d) Au and (e) Ag etched NPSi (1 h etch time). Pores are back-filled with $\mathrm{Al}_{2} \mathrm{O}_{3}$ via ALD prior to FIB milling. (f) Reflectance spectra of NPSi coated with $\mathrm{TiO}_{2}$ via ALD post-etching (lines labelled with metal catalyst used). Reflectance data from 820$860 \mathrm{~nm}$ is omitted due to light-source switching. Inset shows reflectance data, including spectrum for bare Si (blue line).

with $\mathrm{TiO}_{2}$. This process yields a porous, high surface-area functional substrate, while its porosity results in antireflective properties. Nanostructured $\mathrm{TiO}_{2}$ has been explored for applications owing to its anti-reflective and self-cleaning properties. ${ }^{57-59}$ Fig. 2f shows reflectivity measurement $\mathrm{TiO}_{2}$ functionalized NPSi, demonstrating reflectance values between $2 \%$ and $8 \%$ over the UV-visible and short-IR wavelengths for a
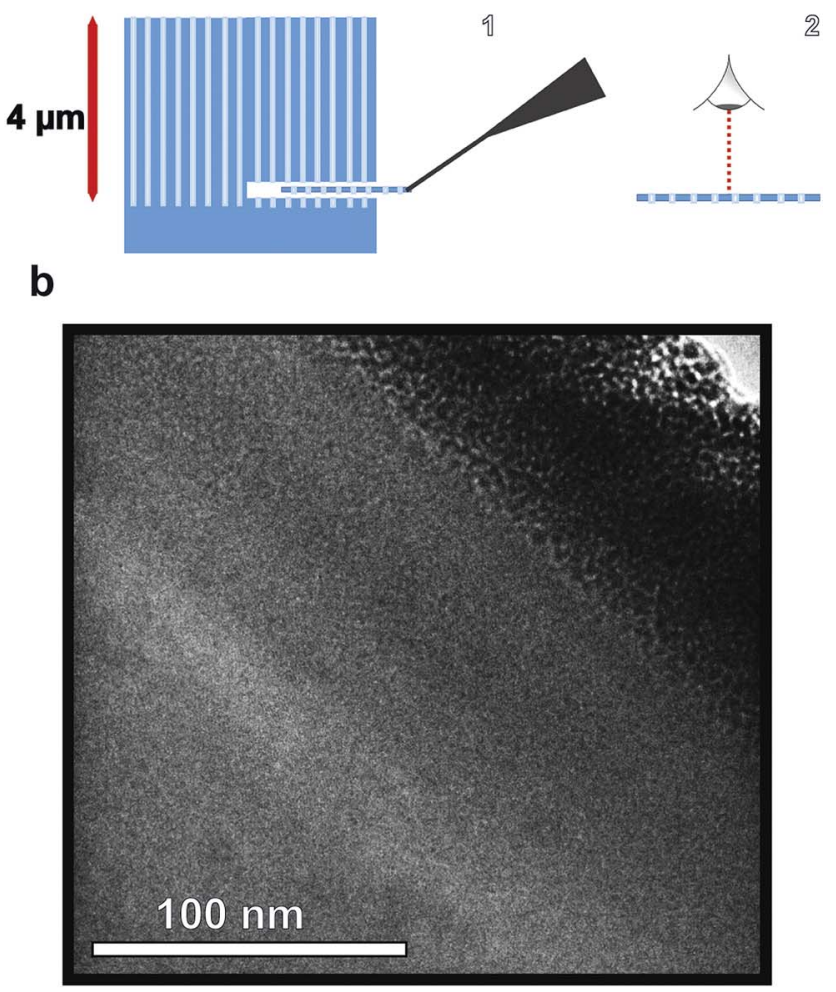

C

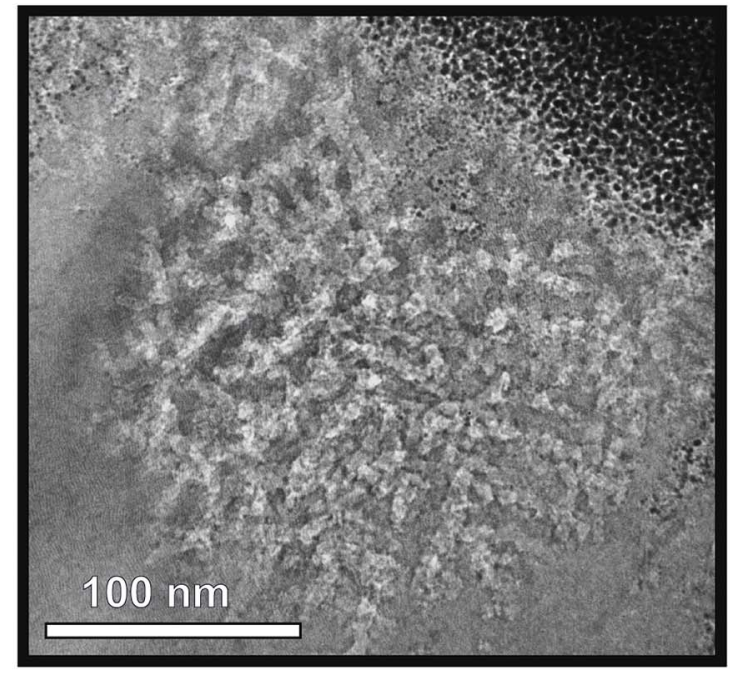

Fig. 3 TEM images of planar lamellae of Si prepared via FIB at a $4 \mu \mathrm{m}$ depth. (a) Schematic of lamellae preparation showing (1) removal of lamella from NPSi via Omniprobe and (2) TEM viewing perspective. (b) Native Si not exposed to the MACE process, and (c) Si with sputtered gold catalyst immersed in MACE solution for 1 hour. The darker contrast area on top-right corner of both images is the platinum protective layer deposited prior to planar sectioning.

both $\mathrm{Au}$ - and $\mathrm{Ag}$-etched Si. While not achieving reflectances as low as those demonstrated for MACE-processed NPSi by Branz et al., which possessed 1-5\% reflectance in the visible range, ${ }^{\mathbf{6 0 , 6 1}}$ the NPSi produced here demonstrates promise due to its smaller pore size, and higher aspect-ratio. With these metrics, 
higher pore densities can be achieved, which correlate to higher functional surface area. Thus, we demonstrate NPSi functionalized with a deposited nanometer-thick layer of $\mathrm{TiO}_{2}$, with the potential of being a material with competitive light absorption and conversion properties.

Coating of nanoscale, ultra-high aspect ratio pores of over 1000:1 has previously been demonstrated for anodized aluminum oxide (AAO). ${ }^{62}$ An SEM image of a FIB milled crosssection (Fig. 4a) and associated EDS analysis (Fig. 4b) confirms conformal $\mathrm{TiO}_{2}$ deposition into high aspect ratio pores to depths of roughly $1 \mu \mathrm{m}$ below the substrate surface. Ti and $\mathrm{O}$ are both present above the dotted line (700 nm, EDS point 1) (Fig. 4b). The pores shown in Fig. 4a are fully filled with $\mathrm{TiO}_{2}$ for characterization, but can also be partially filled to maintain the nanoporous structure of the substrate. EDS point 2, at $1300 \mathrm{~nm}$, shows no Ti presence. $\mathrm{C}$ and Ga are present due to the substrate and surface contamination and ion implantation, respectively. The lack of a Ti signal indicates the absence

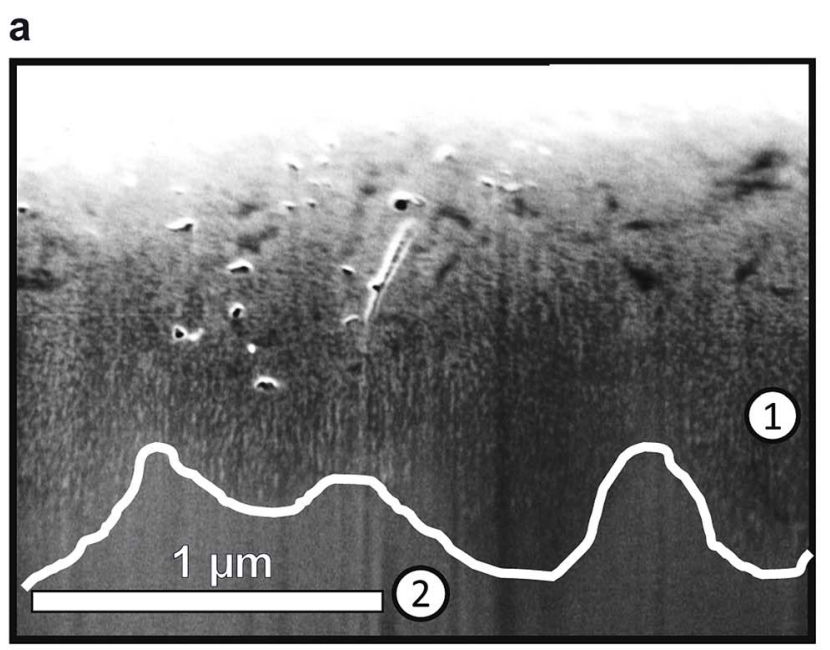

b

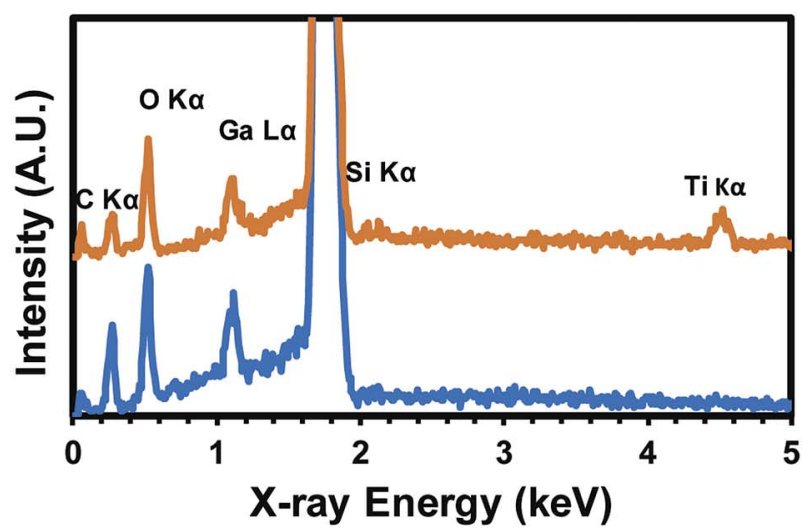

Fig. 4 (a) FIB cross section of NPSi etched with Au islands and coated with $\mathrm{TiO}_{2}$. $\mathrm{TiO}_{2}$-filled pore area is lighter in contrast to silicon background. The white line illustrates lowest visible pore depth along cross-section. (b) EDS analysis of the SEM region shown: scan at $700 \mathrm{~nm}$ (spot 1) shows the presence of $\mathrm{TiO}_{2}$, while a scan at $1300 \mathrm{~nm}$ (spot 2) from surface lacks $\mathrm{TiO}_{2}$ ( $\mathrm{A}$ and $\mathrm{B}$ ). The Si peak is cut off due to a strong signal from the underlying substrate. of the porous regime. The coated NPSi surface was characterized via XPS to confirm the composition of the ALD coating. High resolution element scans confirm the stoichiometry of the $\mathrm{TiO}_{2}$ coating: deconvolution of the $\mathrm{O} 1$ s peak into $\mathrm{TiO}_{2}$ (ref. 63) and $\mathrm{SiO}_{2}$ (ref. 64) yields a O : Ti ratio of $2.3: 1$ (see ESI $\dagger$ for XPS data and analysis). These results demonstrate the realization of NPSi with sub-10 nm, ultra-high aspect ratio pores, which can be made functional via the ALD deposition of $\mathrm{TiO}_{2}$.

\section{Conclusions}

In this work, a MACE process which utilizes sputtered nucleated noble metal nanoislands as catalysts for etching has been introduced. By leveraging interfacial effects and the nature of film formation, sub-5 $\mathrm{nm}$ noble metal islands are nucleated on silicon uniformly over multiple square centimeters. The developed technique is advantageous when compared to other MACE schemes such as nanoparticle deposition and patterned features due to the islands' narrow size distribution and planar interface with the $\mathrm{Si}$, reducing the occurrence of unwanted etching effects resulting from nanoparticle facets and substrate contact surface area. These islands are shown to etch pores with aspect ratios as high as $400: 1$ for both Au and Ag catalysts. The resulting highly porous substrates are then coated with a functional layer of $\mathrm{TiO}_{2}$ via ALD to demonstrate the potential functionality of NPSi. This work introduces a scalable, consistent method of achieving ultra-high aspect ratio sub-10 nm pores, providing a novel platform for a wide range of possible applications.

\section{Acknowledgements}

The authors would like to acknowledge the generous financial support of the Abdul Latif Jameel World Water and Food Security Lab at MIT and the Deshpande Center for Technological Innovation. B. D. Smith receives partial funding from the Natural Sciences and Engineering Research Council of Canada (NSERC). This work was performed in part at the Center for Nanoscale Systems (CNS) at Harvard University, which is part of the National Nanotechnology Infrastructure Network (NNIN), supported by the National Science Foundation (NSF) award no. ECS-0335765. Special acknowledgement is given to N. Ferralis for insightful discussions, and A. Akey and S. Kraemer for assistance with sample preparation.

\section{Notes and references}

1 A. J. Uhlir, Bell Syst. Tech. J., 1956, 35, 333-347.

2 N. Atiwongsangthong, Adv. Sci. Lett., 2013, 19, 3131-3134.

3 Z. Deng and E. C. Alocilja, IEEE Sens. J., 2008, 8, 775-780.

4 T. A. Desai, D. J. Hansford, L. Leoni, M. Essenpreis and M. Ferrari, Biosens. Bioelectron., 2000, 15, 453-462.

5 S. E. Létant, B. R. Hart, A. W. Van Buuren and L. J. Terminello, Nat. Mater., 2003, 2, 391-395.

6 K. Nomura, H. Ohta, A. Takagi, T. Kamiya, M. Hirano and H. Hosono, Nature, 2004, 432, 488-492. 
7 J. Shi, F. Xu, Z. Ma, P. Zhou, L. Zheng, J. Yang, D. Chen and Z. Jiang, Mater. Sci. Semicond. Process., 2013, 16, 441-448.

8 T. K. Chong, J. Bullock, T. P. White, M. Berry and K. J. Weber, IEEE Journal of Photovoltaics, 2015, 5, 538-544.

9 F. Toor, H. M. Branz, M. R. Page, K. M. Jones and H. C. Yuan, Appl. Phys. Lett., 2011, 99, 103501.

10 G. Shi and E. Kioupakis, ACS Photonics, 2015, 2, 208-215.

11 T. D. Dzhafarov, S. S. Aslanov, S. H. Ragimov, M. S. Sadigov and S. A. Yuksel, Vacuum, 2012, 86, 1875-1879.

12 T. R. Gaborski, J. L. Snyder, C. C. Striemer, D. Z. Fang, M. Hoffman, P. M. Fauchet and J. L. McGrath, ACS Nano, 2010, 4, 6973-6981.

13 M. Bayeva, L. Sun, R. K. Mutharasan and M. Ghanefar, Proc. Natl. Acad. Sci. U. S. A., 2015, 109, 15168-15173.

14 N. S. Bennett, N. M. Wight, S. R. Popuri and J.-W. G. Bos, Nano Energy, 2015, 1-7.

15 J. Tang, H.-T. Wang, D. H. Lee, M. Fardy, Z. Huo, T. P. Russell and P. Yang, Nano Lett., 2010, 10, 4279-4283.

16 J.-H. Lee, G. A. Galli and J. C. Grossman, Nano Lett., 2008, 8, 3750-3754.

17 J. Lee, J. Lim and P. Yang, Nano Lett., 2015, 15, 3273-3279.

18 Z. Huang, N. Geyer, P. Werner, J. de Boor and U. Gösele, Adv. Mater., 2011, 23, 285-308.

19 J. Parasuraman, A. Summanwar, F. Marty, P. Basset, D. E. Angelescu and T. Bourouina, Microelectron. Eng., 2014, 113, 35-39.

20 T. L. Andrew, H.-Y. Tsai and R. Menon, Science, 2009, 324, 917-921.

21 V. R. Manfrinato, J. Wen, L. Zhang, Y. Yang, R. G. Hobbs, B. Baker, D. Su, D. Zakharov, N. J. Zaluzec, D. J. Miller, E. A. Stach and K. K. Berggren, Nano Lett., 2014, 14, 4406-4412.

22 C. Chang and A. Sakdinawat, Nat. Commun., 2014, 5, 4243.

23 S. W. Chang, V. P. Chuang, S. T. Boles, C. A. Ross and C. V. Thompson, Adv. Funct. Mater., 2009, 19, 2495-2500.

24 Z. Huang, X. Zhang, M. Reiche, L. Ltu, W. Lee, T. Shimizu, S. Senz and U. Gösele, Nano Lett., 2008, 8, 3046-3051.

25 E. F. Pecora, N. Lawrence, P. Gregg, J. Trevino, P. Artoni, A. Irrera, F. Priolo and L. Dal Negro, Nanoscale, 2012, 4, 2863-2866.

26 J. Wu, H. Zheng, H. Cheng, L. Zhou, K. C. Leong, R. Rajagopalan, H. P. Too and W. K. Choi, Langmuir, 2014, 30, 2206-2215.

27 M. L. Zhang, K. Q. Peng, X. Fan, J. S. Jie, R. Q. Zhang, S. T. Lee and N. B. Wong, J. Phys. Chem. C, 2008, 112, 4444-4450.

28 H. Asoh, F. Arai and S. Ono, Electrochim. Acta, 2009, 54, 5142-5148.

29 X. Li, Curr. Opin. Solid State Mater. Sci., 2012, 16, 71-81.

30 K. Tsujino and M. Matsumura, Electrochim. Acta, 2007, 53, 28-34.

31 K. Tsujino and M. Matsumura, Adv. Mater., 2005, 17, 10451047.

32 K. Peng, A. Lu, R. Zhang and S.-T. Lee, Adv. Funct. Mater., 2008, 18, 3026-3035.

33 G. Liu, K. L. Young, X. Liao, M. L. Personick and C. A. Mirkin, J. Am. Chem. Soc., 2013, 135, 12196-12199.

34 M. K. Dawood, S. Tripathy, S. B. Dolmanan, T. H. Ng, H. Tan and J. Lam, J. Appl. Phys., 2012, 112.
35 N. Geyer, B. Fuhrmann, Z. Huang, J. De Boor, H. S. Leipner and P. Werner, J. Phys. Chem. C, 2012, 116, 13446-13451.

36 O. J. Hildreth, W. Lin and C. P. Wong, ACS Nano, 2009, 3, 4033-4042.

37 C. Chartier, S. Bastide and C. Lévy-Clément, Electrochim. Acta, 2008, 53, 5509-5516.

38 B. D. Smith, J. J. Patil, N. Ferralis and J. C. Grossman, ACS Appl. Mater. Interfaces, 2016, 8, 8043-8049.

39 P. Andreazza, C. Andreazza-Vignolle, J. P. Rozenbaum, A. L. Thomann and P. Brault, Surf. Coat. Technol., 2002, 151-152, 122-127.

40 B. F. Usher, Appl. Surf. Sci., 1985, 22-23, 506-511.

41 Y. Chung, H. Koo, K. K. Lee, M. Hamilton, D.-J. Kim, F. Tong, J. Goswami, V. Davis and M. Park, Electron. Lett., 2014, 50, 623-624.

42 A. Fujishima, X. Zhang and D. A. Tryk, Surf. Sci. Rep., 2008, 63, 515-582.

43 K. Nakata and A. Fujishima,J. Photochem. Photobiol., C, 2012, 13, 169-189.

44 K. Hashimoto, H. Irie and A. Fujishima, AAPPS Bull., 2007, 17, 12-28.

45 M. Reiners, K. Xu, N. Aslam, A. Devi, R. Waser and S. Hoffmann-Eifert, Chem. Mater., 2013, 25, 2934-2943.

46 X. Chen and S. S. Mao, Chem. Rev., 2007, 107, 2891-2959.

47 J. Bai and B. Zhou, Chem. Rev., 2014, 114, 10131-10176.

48 S. P. Scheeler, S. Ullrich, S. Kudera and C. Pacholski, Nanoscale Res. Lett., 2012, 7, 450.

49 T. Wen and S. A. Majetich, ACS Nano, 2011, 5, 8868-8876.

50 B. H. Kemmenoe and G. R. Bullock, J. Microsc., 1983, 132, 153-163.

51 R. Conrad and M. Harsdorff, Int. J. Electron., 1990, 69, 153-167. 52 F. Aqra and A. Ayyad, Appl. Surf. Sci., 2014, 314, 308-313.

53 L. Vitos, A. V. Ruban, H. L. Skriver and J. Kollár, Surf. Sci., 1998, 411, 186-202.

54 J. K. Bal and S. Hazra, Phys. Rev. B, PRB, 2007, 75, 1-6.

55 S. S. Yoon and D. Y. Khang, Langmuir, 2015, 31, 1054910554.

56 W. Chern, K. Hsu, I. S. Chun, B. P. De Azeredo, N. Ahmed, K. H. Kim, J. M. Zuo, N. Fang, P. Ferreira and X. Li, Nano Lett., 2010, 10, 1582-1588.

57 Q. Mao, D. Zeng, K. Xu and C. Xie, RSC Adv., 2014, 4, 5810158107.

58 X. Zhang, A. Fujishima, M. Jin, A. V Emeline and T. Murakami, J. Phys. Chem. B, 2006, 110, 25142-25148.

59 M. Faustini, A. Grenier, G. Naudin, R. Li and D. Grosso, Nanoscale, 2015, 7, 19419-19425.

60 J. Oh, T. G. Deutsch, H.-C. Yuan and H. M. Branz, Energy Environ. Sci., 2011, 4, 1690.

61 H. M. Branz, V. E. Yost, S. Ward, K. M. Jones, B. To and P. Stradins, Appl. Phys. Lett., 2009, 94, 1-4.

62 J. W. Elam, D. Routkevitch, P. P. Mardilovich and S. M. George, Chem. Mater., 2003, 15, 3507-3517.

63 M. Gebhard, F. Mitschker, M. Wiesing, I. Giner, B. Torun, T. de los Arcos, P. Awakowicz, G. Grundmeier and A. Devi, J. Mater. Chem. C, 2016, 4, 1057-1065.

64 A. U. Alam, M. M. R. Howlader and M. J. Deen, ECS J. Solid State Sci. Technol., 2013, 2, 515-523. 